\title{
Diversidade e mercado de trabalho no
}

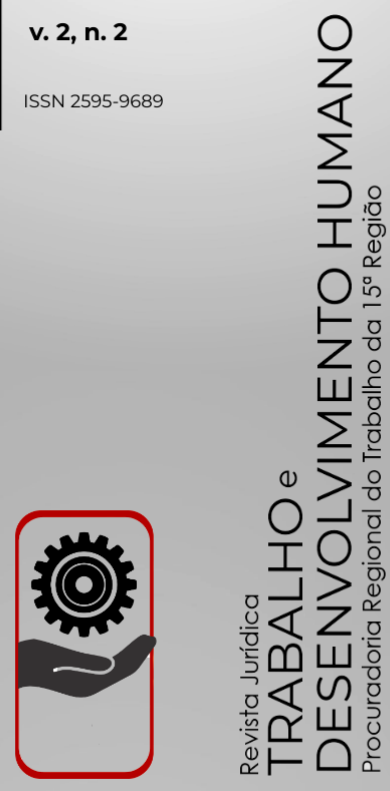

Received: 12.12 .2019 Accepted: 17.12.2019

https://doi.org/10.33239/rtdh.v2i2.60

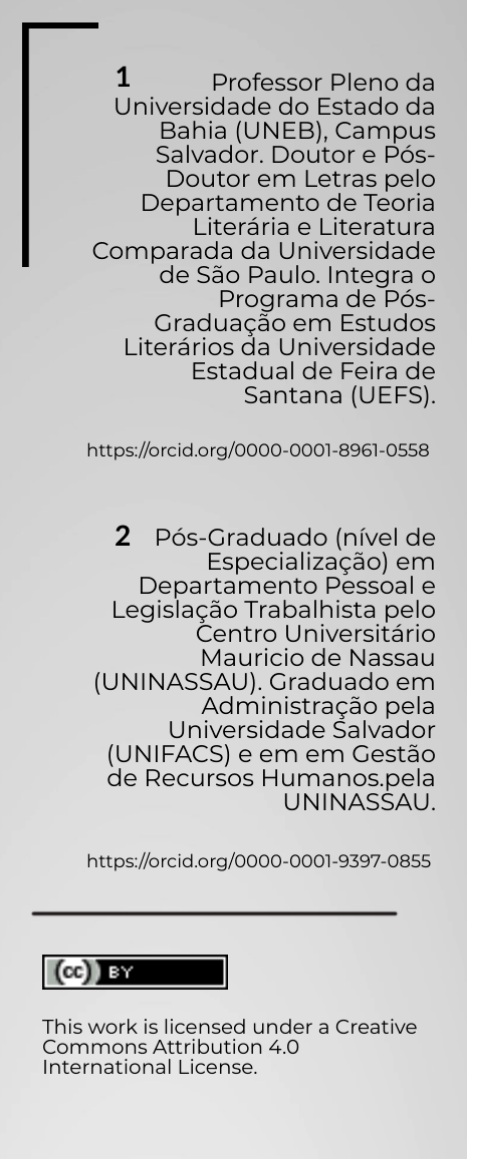

Brasil

\author{
Diversity and job market in Brazil \\ Diversidad y mercado de trabajo en Brasil
}

\begin{abstract}
Suênio Campos de Lucena' Cristiano Vileno Conceição Santos ${ }^{2}$
\end{abstract}

\begin{abstract}
RESUMO
Este artigo busca refletir sobre os avanços e retrocessos que envolvem o mercado de trabalho formal e o segmento LGBT. Como essa questão segue fortemente na agenda da sociedade e nas instâncias política, familiar, trabalhista etc., este tema é de enorme relevância, sobretudo, quando organizações começam a assumir o discurso do respeito à diferença e de mais inclusão a grupos historicamente excluídos, abrindo diálogo e acesso ao trabalho formal. Assim, realizamos breve levantamento histórico de leis nos Estados Unidos, Europa e Brasil, a fim de verificarmos a questão da ocupação formal da comunidade LGBT, particularmente, de transgêneros/as e travestis, tendo em vista a atuação de partidos políticos que se amparam em bancadas religiosas no sentido de barrarem a eventual aprovação de leis e conquistas de direitos desse grupo, uma vez que o Congresso Nacional tem se negado a aprovar leis para este segmento, no Brasil avanços impostos pelo STF, Supremo Tribunal Federal. A partir da Teoria Queer e de estudos como os de Judith Butler, buscamos refletir sobre mercado de trabalho e este grupo, um contexto que oscila entre resistência e gradual aproximação a um discurso e prática empresariais na direção do respeito, da aceitação e da inclusão. É dessa forma que o mercado formal de trabalho e a sociedade brasileira se dividem entre a aceitação e a recorrência de situações que revelam intolerância e dificuldade de absorção dessa mão de obra.
\end{abstract}

PALAVRAS-CHAVES: Travestis; Ocupação; Trabalho; recrutamento; Empresas.

\section{ABSTRACT}

This article seeks to reflect on advances and setbacks involving the formal labor market and the LGBT segment. As this issue follows in the social agenda (politics, family, labor, etc.), this theme is of great relevance, especially when Organizations begin to assume the discourse of respect for difference and more inclusion to historically excluded groups, opening dialogue and access to formal work. Thus, we conducted a brief historical survey of laws in the United States, Europe and Brazil in order to verify the issue of formal occupation of the LGBT community, particularly transgender and transvestites, in view of the performance of political parties based on religious benches in order to block the eventual approval of laws and rights gains of this group, given that the National Congress has refused to approve achievements for this segment, in general, advances imposed by the Supreme Court. Basing on Queer Theory and studies such as those by Judith Butler, we seek to reflect on how the labor market has absorbed this group a context that oscillates between resistance and gradual approach to a business discourse and practice towards inclusion, despite constant backlash. This is how the formal labor market and Brazilian society are divided between acceptance and the occurrence of situations that reveal intolerance and difficulty in absorbing this workforce.

KEY-WORDS: Travestis; Occupation; Job; recruitment; Companies.

RESUMEN

Este artículo busca reflexionar sobre los avances y retrocesos que involucran al mercado laboral 


\begin{abstract}
formal y al segmento LGBT. Dado que este tema está muy presente en la agenda de la sociedad y en instancias políticas, familiares, laborales, etc., este tema es de enorme relevancia, especialmente cuando las organizaciones comienzan a asumir el discurso de respeto a la diferencia y mayor inclusión de los grupos históricamente excluidos, abriendo el diálogo y el acceso al trabajo formal. Así, realizamos un breve repaso histórico de las leyes en Estados Unidos, Europa y Brasil, para verificar el tema de la ocupación formal de la comunidad LGBT, en particular de los transexuales y travestis, en vista de las acciones de los partidos políticos que se apoyan en bancos religiosos para impedir la eventual aprobación de leyes y logros de derechos de este grupo, ya que el Congreso Nacional se ha negado a aprobar las leyes para este segmento, en Brasil los avances impuestos por el STF, la Corte Suprema Federal. A partir de la Teoría Queer y estudios como los de Judith Butler, buscamos reflexionar sobre el mercado laboral y este grupo, un contexto que oscila entre la resistencia y la aproximación gradual a un discurso y práctica empresarial en la dirección del respeto, la aceptación y la inclusión. Es así como el mercado laboral formal y la sociedad brasileña se dividen entre la aceptación y recurrencia de situaciones que revelan intolerancia y dificultad para absorber esta fuerza de trabajo.
\end{abstract}

PALABRAS CLAVE: Travesties; Ocupación; Trabajo; Reclutamiento; Empresas.

\title{
INTRODUÇÃO
}

Este artigo objetiva lançar reflexões sobre a ocupação formal da comunidade LGBT [lésbicas, gays, bissexuais, travestis e transexuais] em organizações públicas e privadas brasileiras, a partir de uma revisão histórica acerca da legislação internacional e brasileira sobre essa questão, bem como, sobre iniciativas empresariais de enfrentamento ao preconceito e em prol da inclusão e do respeito à diversidade. Tendo por base teórica a Teoria Queer e os estudos de Judith Butler, desejamos pensar sobre como essas organizações têm lidado com os processos de recrutamento, seleção e contratação dessa comunidade, no nosso caso, em especial, transgêneros e travestis.

Essa análise da absorção do mercado de trabalho para LGBTs atende à seguinte Metodologia de Pesquisa: a) Levantamento de leis e normas sobre o tema nos Estados Unidos e Europa, a fim de realizarmos uma análise comparativa entre essas realidades e a brasileira; b) Apresentação de dados e ocorrências que comprovam as barreiras e dificuldades de contratação devido à restrição e preconceito de orientações sexuais diversas da heterossexual. Por fim: c) Breves relatos de ações e iniciativas referentes a políticas de inclusão por parte de algumas organizações no enfrentamento ao preconceito e que 
sinalizam respeito e sinais de abertura do mundo corporativo à comunidade LGBT.

A intenção de verificar a legislação e os dados trabalhistas ocorre a fim de buscarmos entender sobre como o mercado de trabalho formal tem lidado com esse segmento. A realidade indica tanto preconceito e resistência quanto o início de aceitação e respeito por parte de muitas organizações, através da adoção de políticas de contratação de LGBTs. Essa divisão de posicionamentos que atravessa esse tema reflete algo bastante recorrente neste momento na sociedade brasileira: A grande pulverização de posições, o que explica recuos e avanços quanto à questão das relações de trabalho e este segmento.

Assim sendo, esta pesquisa busca compreender a situação atual das ocupações no mercado formal de trabalho perante à questão da diversidade num momento em que as organizações começam a assumir o discurso do respeito à diversidade, avessas ao preconceito em seus quadros, e, em alguns casos, realizando ações de discussão e abertura, atentas à pressão social que repudia homofobia e, também, racismo, machismo, gordofobia etc., presentes em alguns ambientes de trabalho e percebidos na indicação de cargos de confiança.

\section{DIVERSIDADE E LEGISLAÇÃO NA EUROPA E NOS ESTADOS UNIDOS}

Vale a pena iniciarmos essa reflexão citando brevemente a situação desse tema nos Estados Unidos e em alguns países da Europa a fim de lançarmos uma análise comparativa entre esses países e a realidade brasileira.

A Declaração Universal dos Direitos Humanos de 1948 defende a ideia da proteção e legitimidade política voltada para homens e mulheres. Contudo, em relação ao gênero, essa abrangência reforça a classificação binária homem/mulher:

Considerando que os povos das Nações Unidas reafirmaram, na Carta da ONU, sua fé nos direitos humanos fundamentais, na dignidade e no valor do ser humano e na igualdade de direitos entre homens e mulheres, e que decidiram promover o progresso social e melhores condições de vida em uma liberdade mais ampla... a Assembleia Geral proclama a presente 
Declaração Universal dos Diretos Humanos como o ideal comum a ser atingido por todos os povos e todas as nações (UNIC, 2009, p. 3).

Em Junho de 2015, uma decisão da Suprema Corte dos Estados Unidos estendeu o reconhecimento da legalidade da união civil entre pessoas do mesmo sexo em todos os estados norte-americanos, inclusive, naqueles onde havia restrições, obrigando-os a registrar essas uniões em seus cartórios. Contudo, algumas decisões do Presidente dos Estados Unidos, Donald Trump, têm provocado revoltas por parte de ativistas da causa LGBT. Em 2017, meses após assumir, ele desfez uma importante conquista para esta causa, que garantia a possibilidade de transgêneros ingressarem nas Forças Armadas. Além disso, ele tem realizado restrições a programas e ações afirmativas de inclusão desse contingente em universidades (MARTÍ, 2018, p.1), recuando em diversas conquistas legitimadas pela gestão anterior, de Barack Obama.

Segundo o Procurador-Geral da República, Jeff Sessions, Donald Trump alega que a proteção no ambiente de trabalho de um indivíduo é garantida pela Lei dos Direitos Civis, de 1964, portanto, trata biologicamente os sexos masculino e feminino, sem distinções. Para Sessions, a questão biológica do sexo restringe tanto o sexo masculino quanto o feminino, sendo que a questão em foco é a criminalização contra transgêneros, algo que deixou de ser assegurado. Após essa decisão, o Departamento de Justiça emitiu parecer informando que a própria Lei dos Direitos Civis não protege o trabalhador em casos de identidade de gênero, o que gerou uma lacuna no entendimento sobre a diferença de gênero nas organizações e a importância de legislações especificas que assegurem o respeito às diferenças.

A Europa segue caminho diferente, ao se abrir para conquistas LGBTs (algo, vale lembrar, duramente conquistado), seja na oferta de contratações e, também, na proteção, reconhecimento e garantias legais à comunidade. Segundo dados da ILGA (International lesbian, gay, bissexual, trans and intersex association), países como Alemanha, Bélgica, Canadá, Espanha, Hungria, Noruega, Portugal, Reino Unido, Suécia, entre outros, já equipararam direitos LGBTs, como adoção, pensão, herança e união estável, aos dos 
heterossexuais.

A legislação de Portugal, por exemplo, abrange leis anti-discriminação no contexto da identidade de gênero, sendo um dos países da União Européia que abrange mais legislações e políticas públicas de inclusão que aborda não somente a questão das proteções física e moral, mas, também, direitos básicos, como ter o nome social nos documentos de uso pessoal, o que garante integridade e acesso a serviços públicos e privados sem passar pelo constrangimento de alguém insistir em não reconhecer o nome social.

A médica paraibana Camille Cabral, por exemplo, foi a primeira transexual eleita em Paris, enquanto no Brasil casos de travestis eleitas deputadas e vereadoras (como a dançarina baiana Leo Kret, que deteve mandato legislativo na Câmara de Salvador, entre os anos 2009/2012; Érica Malunguinho e Tammy Miranda, respectivamente, deputada e suplente de vereador em São Paulo) ainda são exceções e costumam chamar atenção pelo ineditismo, uma vez que há forte resistência em enxergá-las/os como profissionais capacitados/as para atuar como gestores/as e atuantes nos mercados corporativo, empresarial e/ou industrial.

\section{A QUESTÃO LGBT E A LEGISLAÇÃO BRASILEIRA}

No Brasil, a luta pela conquista de direitos e pela ocupação do mercado formal tem ocorrido nas esferas política e legal (no Direito), expondo bastidores e números que impressionam e expõem uma dura realidade enfrentada por essa comunidade. Segundo dados da ONU, a Organização das Nações Unidas, o Brasil é o país onde mais se matam lésbicas, gays, transgêneros e travestis ${ }^{1}$. Os números são alarmantes e exibem execuções

\footnotetext{
${ }^{1}$ No Brasil, a cada três dias um homossexual é assassinado em virtude de sua orientação sexual e o Observatório de Segurança (2010) estima que o risco de um travesti ou transexual ser assassinada é 259 vezes superior a dos gays e lésbicas, pois além de sua identidade sexual, a grande maioria trabalha no mercado informal ou com prostituição (ABLGT, 2010).
} 
extremadas, asfixia, tortura, mortes por armas brancas, enforcamentos, enfim, toda ordem de assassinatos, configurando os chamados crimes de ódio e que têm sido denunciados por associações como GGB, Grupo Gay da Bahia, por apresentarem baixa resolução por parte da Polícia.

Nos últimos anos, as poucas conquistas obtidas pela comunidade LGBT brasileira têm ocorrido a partir de decisões tomadas pelo STF, Supremo Tribunal Federal, que, diante da omissão do Legislativo, acaba julgando casos individuais e/ou coletivos e impondo a tribunais e instâncias federais e estaduais o cumprimento e a não contestação às suas decisões, a partir da chamada Súmula Vinculante. Este foi o caso da união civil estável, que reconheceu, por unanimidade, em maio de 2011, o direito à união estável homoafetiva, bem como, herança, plano de saúde e previdência, similares à união heterossexual. Contudo, trata-se de processo que deve ser feito mediante pedido de cada casal à Justiça e, depois, obter assento no Registro Civil. Outra conquista relevante ocorreu em Junho de 2019, quando o STF aprovou a criminalização da homofobia, associando-o ao crime de racismo. O relator, seguido pelo voto da maioria, foi o ministro Celso de Mello.

A despeito dessas conquistas, a Bancada Evangélica, aliada a partidos políticos de espectro conservador, têm atuado fortemente no sentido de não avançar essa pauta, ou seja, em barrar a aprovação de leis que dêem direitos aos homossexuais similares aos dos heterossexuais. A chamada bancada $\mathrm{BBB}^{2}$, que defende interesses de evangélicos, das armas e do agronegócio, tem se colocado frontalmente contrária a avanços nos costumes. Em geral, são siglas que integram a base de apoio do Presidente da República, Jair Bolsonaro, que têm como sustentação militares e pastores (Marco Feliciano, Silas Malafaia etc.), que apresentam programas em grandes templos veiculados por grupos de comunicação, como Record e outras emissoras de rádio e TV, comandadas por grupos religiosos onde essa temática é silenciada e/ou duramente combatida.

\footnotetext{
${ }^{2}$ Codinome adotado pela imprensa brasileira para designar partidos e políticos em torno de interesses comuns, agrupados a fim de defender interesses conservadores: Bancadas armamentista (da bala); ruralista (do boi) e evangélica (da Bíblia).
} 
A despeito da não aprovação pelo Congresso Nacional de leis favoráveis à causa LGBT $^{3}$, algo defendido por poucos políticos, como o ex-deputado federal Jean Wyllys, e a exsenadora Marta Suplicy, nos últimos anos leis, normas e portarias de alguns ministérios têm garantido avanços a essa comunidade, como é o caso da Portaria 457, de Agosto de 2008, que garante a cirurgia de redesignificação sexual feita pela rede pública de saúde, o SUS, Serviço Único de Saúde. Em dez anos, o SUS já realizou centenas de intervenções. Além dessa legislação específica, a Portaria 233 também garantiu Nome Social aos Servidores Públicos transexuais e travestis (Ministério do planejamento, orçamento e gestão, em 18 de maio de 2010). Outra conquista foi a Resolução 002/2008, que normatizou a Inclusão do Nome Social de Travestis e transexuais nos Registros Escolares das Escolas da Rede Municipal de Educação de Belo Horizonte; a Portaria 675, de 2006, que tratou de Nome Social para Usuários de Saúde, independentemente do que consta no Registro Civil; a Resolução do CFM, Conselho Federal de Medicina, que trata da Cirurgia de Transgenitalização para Transexuais, de Agosto de 2010, e, por fim, a Instrução Normativa $1.718 / 2017^{4}$ que facilitou a mudança de nome, o chamado Nome Social, prática extensiva à prova do ENEM, Exame Nacional do Ensino Médio, e em documentos como CPF, emitido pela Receita Federal.

Além disso, os LGBTs têm tido uma abordagem menos sensacionalista por parte da mídia, quando esta evita associar travestis e transgêneros, por exemplo, não apenas a atividades da noite, prostituição e criminalidade, mas ao realizar uma cobertura voltada para denúncias de situações de homofobia. Nos últimos anos, telenovelas ${ }^{5}$, filmes, peças e livros,

\footnotetext{
${ }^{3}$ Um Projeto de Lei de 2014 apresentado pelo Deputado Federal Salvador Zimbaldi (PDT/SP) defendeu que casais homoafetivos sejam impedidos de aparecer em propagandas voltadas para o público adolescente e infantil. Se aprovado, só poderão aparecer em anúncios e propagandas famílias formadas por homem e mulher. ${ }^{4}$ Instrução Normativa 1.718/2017 atende ao Decreto 8.727, de 28 de abril de 2016, que dispõe sobre o uso do nome social e o reconhecimento da identidade de gênero de travestis e transexuais no âmbito da administração pública federal, autárquica e fundacional.

${ }^{5}$ A telenovela A Força do Querer, de Glória Perez (Globo; Abril/Outubro de 2017) mostrou uma travesti que canta, dança e trabalha e que ainda era motorista de um casal rico. Além dele, a novela abordou o processo de descoberta e as agruras familiares vividas pela jovem transexual Ivana. Sem associá-los à marginalidade, ao escracho ou à bizarrice, a novela mostrou o cotidiano profissional e familiar dessas personagens a partir de situações de enfrentamento ao ódio, ao desprezo e escárnio, expondo as dificuldades dessas pessoas em conseguir emprego no mercado formal de trabalho. Diversas produções têm dado um tratamento mais
} 
entre outros, têm humanizado essas pessoas, distanciando-as da abordagem caricatural. Após uma cobertura onde imperavam o festivo, o bizarro, o estereótipo e o espalhafato, a mídia tem seguido um direcionamento de mais respeito à diferença e à diversidade, embora existam setores bastante resistentes, como nos casos de anúncios publicitários de marcas como Avon e O Boticário em que aparecem casais gays, o que provoca levas de apoio e, também, campanhas de boicote: “Os discursos veiculados pela mídia acionam poderosos efeitos de verdade, que podem contribuir significativamente para a construção das identidades dos sujeitos" (FELIPE, 2006, p. 13).

Segundo dados que constam do Relatório Anual da ANTRA, Associação Nacional das Travestis, a maior resistência do mercado de trabalho é em relação à contratação de travestis, o Essa realidade trabalhista se deve ao preconceito e também, em parte, à dificuldade de entendimento coletivo sobre alguém que se autodeclara travesti.

Para Joseli Silva, o termo travesti significa a nomeação de pessoas que têm: “Um corpo biologicamente masculino e identidade de gênero feminina. Para atingir o ideal da aparência do gênero adotado e apresentar sua identidade, essas pessoas tomam hormônios femininos, usam silicone e realizam... transformações corporais" (SILVA, 2009, p. 136). É dessa forma que travesti é compreendida de diferentes formas em diferentes contextos. Há um problema semântico que envolve associações do termo "travesti" a transgênero e transexual para nomear pessoas que apresentam dissonância entre corpo biológico e identidade de gênero. A tradução de travesti para o inglês é transvestite: "Contudo, o termo em inglês não se coaduna com os sujeitos aqui enfocados, já que ele é utilizado para nomear homens que se vestem 'eventualmente' como mulheres” (SILVA, 2009, p. 135). É importante ressaltar que

humanizado às travestis e transexuais. São os casos do documentário Divinas Divas (2017), que aborda a primeira geração de travestis brasileiras (Rogéria, Valéria etc.), e de filmes como Kinky Boots (2005), que têm abordado o tema centrado nas dificuldades e problemas, como o preconceito nos ambientes familiar e organizacional. 
travestis não costumam realizar a Cirurgia de Redesignificação Sexual ${ }^{6}$, ou seja, mudar de gênero.

Enquadrar ou julgar alguém estabelecendo padrões do certo ou errado em relação à sua sexualidade fere a subjetividade, uma vez que existem inúmeros modelos de se exercêla. Sobre essa questão, para Judith Butler não existe uma identidade de gênero por trás das expressões de gênero, uma vez que identidade trata-se de algo culturalmente constituído, pois:

De fato, ele pode ser considerado um dos instrumentos fundamentais, enfim, necessários para fazer a transição e tornar a vida vivível, proporcionando a base para que uma pessoa se desenvolva como um sujeito corporal. Por outro lado, o instrumento assume vida própria e pode tornar a vida mais difícil para aquelas pessoas que sofrem por serem patologizadas e que perdem certos direitos e liberdades, incluindo a custódia das crianças, o emprego e a moradia, devido ao estigma inerente ao diagnóstico ou, mais precisamente, devido ao estigma que o diagnóstico reforça e promove. Embora fosse melhor que vivêssemos num mundo no qual não houvesse tal estigma - nem tal diagnóstico -, ainda não vivemos num mundo assim. Além disso, a profunda suspeita a respeito da saúde mental das pessoas que transgridem as normas de gênero estrutura a maioria dos discursos e instituições que regulam questões acerca do direito e da possibilidade de ajuda financeira e assistência médica (BUTLER, 2009, p.109).

Para Franco Reinaudo e Laura Bacellar: "Gênero é sinônimo de identidade sexual que a pessoa acredita ter sendo ela masculina ou feminina, sendo essa identidade uma convicção que o indivíduo possui entre ser homem ou mulher" (REINAUDO e BACELLAR, 2008, p. 22); ou seja, gênero não depende da condição biológica de nascimento, mas da autoafirmação do sujeito, seja feminina ou masculina. Assim, é possível que alguém do sexo masculino ou feminino seja transexual sem realizar a cirurgia de reversão sexual, pois se trata de condição pessoal, a qual somente o/a mesmo/a pode e deve decidir. Segundo Márcia Arán e Daniela

${ }^{6}$ A cirurgia de redesignação sexual, transgenitalização, ou neofaloplastia, popularmente conhecida como cirurgia de mudança de gênero, é feita com o objetivo de adequar as características físicas e dos órgãos genitais da pessoa transgênero, de forma que esta pessoa possa ter o corpo adequado ao que considera adequado para si. Informações retiradas em: https://www.tuasaude.com/cirurgia-de-transgenitalizacão. 
Murta: "Alguns homens e mulheres transexuais podem desejar a cirurgia de transgenitalização pela exclusiva necessidade de reconhecimento social mais amplo, o que nos faz pensar que a cirurgia não necessariamente seria indicada se vivêssemos num mundo onde a diversidade de gênero seja possível" (ARÁN e MURTA, 2009, p. 21).

Judith Butler vê essa questão como construção de gênero:

O gênero não deve ser meramente concebido como a inscrição cultural de significado num sexo previamente dado (uma concepção jurídica); tem de designar também o aparato mesmo de produção mediante o qual os pró prios sexos são estabelecidos. Resulta daí que o gênero não está para a cultura como o sexo para a natureza; ele também é o meio discursivo/cultural pelo qual "a natureza sexuada" ou "um sexo natural" é produzido e estabelecido como "pré-discursivo", anterior à cultura, uma superfície politicamente neutra sobre a qual age a cultura (BUTLER, 2003, p. 25).

Uma vez que os espaços e ambientes de trabalho são reflexos da visão de mundo e de um certo senso comum que permeia as relações humanas, que, em geral, reiteram a ideia em torno da heteronormatividade desde o nascimento de alguém, evidentemente que o mercado de trabalho reflete essa realidade, dividida entre rejeição, episódios recorrentes de crimes de ódio, e eventuais atos de inclusão, respeito e aceitação. No caso das organizações, segundo Luiz Cassiano Mecchi: "Os dilemas organizacionais estão entre admitir ou não um candidato declaradamente LGBT, conceder ou não os mesmos direitos e punir ou ignorar os atos de discriminação" (MECCHI, 2007, p. 22). Ou seja, se, de um lado, há frequentes relatos de organizações com episódios de preconceito, diga-se de passagem, não apenas em relação à orientação sexual, esta pesquisa destaca ações de inclusão e respeito à diversidade.

\section{EMPREGO, ORGANIZAÇÕES E DIVERSIDADE NO BRASIL}

No mundo corporativo, são frequentes os entraves em torno da contratação de LGBTs, em especial, travestis e transgêneros, o que tem provocado baixa taxa de ocupação no 
mercado formal. Tanto o setor público quanto corporações da iniciativa privada ainda oferecem resistência na absorção desses dois segmentos, mesmo que graduados, isso porque são restrições que não se referem à formação, mas ao preconceito, conforme atesta Nádia Lapa: “Ainda que elas queiram arranjar um emprego com rotina, horário de trabalho e carteira assinada, o preconceito fica evidente quando se candidatam a uma vaga" (LAPA, 2013, p. 13).

Uma vez que essas pessoas ainda costumam ser associadas à prostituição e a trabalhos noturnos e artísticos, como canto, dança, atuação, performance e esquetes de humor, ou restritos a salões de beleza (como cabeleireiras, maquiadoras e manicures), as organizações brasileiras costumam seguir esse olhar, com frequência, relutando em contratá-las, apesar de, muitas vezes, se tratarem de profissionais graduadas/os, o que fere o principal conceito do processo de seleção de pessoas, segundo o teórico da Administração, Idalberto Chiavenato ${ }^{7}$ :

A seleção de pessoas funciona como uma espécie de filtro que permite que apenas algumas pessoas possam ingressar na organização: aquelas que representam características desejadas. Em termos mais amplos, a seleção busca, dentre os vários candidatos recrutados, aqueles que são mais adequados aos cargos existentes na organização, visando manter ou aumentar a eficiência e o desempenho do pessoal, bem como a eficácia da organização (CHIAVENATO, 1999, p. 107).

Talvez por isso, em muitos casos, o campo de trabalho da travesti e da transexual, por exemplo, permaneça restrito a apresentações em casas noturnas ou ao ambiente da rua algo que ocorre nem sempre devido à falta de estudo formal e/ou graduação, mas visando obtenção de renda, uma vez que 90\% (noventa por cento) das travestis brasileiras, por exemplo, segundo dados apresentados da ANTRA, não conseguem ser absorvidas pelo mercado formal. Conforme Fleury e Torres: “Quando um indivíduo é reconhecido como

\footnotetext{
${ }^{7}$ Idalberto Chiavenato é um estudioso da área de Administração e Recursos Humanos, sendo um dos autores brasileiros de maior destaque nessa áreas. Seu livro de maior relevância é Teoria Geral da Administração (2004). Ref.: https://www.sunoresearch.com.br/tudo-sobre/idalberto-chiavenato/">.
} 
pertencente a um grupo minoritário, ele já se encontra em posição de desvantagem em relação aos demais indivíduos da sociedade em questão, pertencentes aos grupos majoritários" (FLEURY e TORRES, 2010, p.59). Dentro do contexto citado se conclui, portanto, que tanto a travesti quanto a transgênero sofrem forte resistência na hora da entrevista e da seleção.

Segundo pesquisas realizadas pelo Plantão Plomo no Brasil, uma em cada cinco empresas se recusa a contratar homossexuais com medo de que a imagem da companhia fique associada àquele funcionário, fazendo com que essas empresas percam seus clientes. Enquanto isso, a mesma pesquisa mostra que $68 \%$ das pessoas já presenciaram algum tipo de homo e transfobia no ambiente de trabalho.

É dessa forma que a realidade da comunidade LGBT, particularmente de travestis e transexuais, é permeada pela luta diária de conquista de absorção pelo mercado formal de trabalho, sobretudo, em atividades que as distanciem de casas noturnas, "nichos" que costumam ser associadas e "confinadas", conforme descrito no site Transempregos:

Existe no Brasil toda uma população com capacidade e apta a contribuir com a sociedade e à geração de riquezas, que é impedida e muitas vezes atirada na marginalidade, unicamente em razão do preconceito. Além disso, grande parte das pessoas transgênero oculta sua condição a fim de evitar violências e discriminações, sendo obrigadas a uma vida de desconforto pela necessidade de ocultação ou negação de suas identidades (TRANSEMPREGOS, 2018, p.1).

Com frequência, matérias que tratam do tema emprego e diversidade destacam as dificuldades de LGBTs, em especial, de travestis e transexuais, no momento da entrevista de emprego e contratação. Elas costumam denunciar situações onde várias enviam currículos, mas as organizações não as convocam quando percebem que se tratam de travestis/transexuais, situação relatada por Mateus França, que enviou noventa currículos em quatro meses. Segundo ele: "Colocava meu nome e também o nome social no currículo. As pessoas olhavam para mim e não entendiam e eu sabia que não iam me contratar. Não é à toa que 
distribuí tanto currículo para ser chamado para apenas uma vaga. O mercado de trabalho para pessoas trans é bem preconceituoso" (G1, 2017, p.1).

Outro caso foi do homem trans Miguel Gabriel, que, após ter seu currículo avaliado, foi convocado para uma entrevista, mas, ao chegar no local e o recrutador perceber que se tratava de um homem transexual, não realizou a contratação. Casos como esses refletem a realidade da falta de uma política pública de inclusão LGBT no mercado de trabalho formal, embora a Constituição Federal garanta a proteção contra a discriminação:

É proibida a adoção de qualquer prática discriminatória e limitativa para efeito de acesso à relação de trabalho, ou de sua manutenção, por motivo de sexo, origem, raça, cor, estado civil, situação familiar, deficiência, reabilitação profissional, idade, entre outros, ressalvadas, nesse caso, as hipóteses de proteção à criança e ao adolescente previstas no inciso XXXIII do art. 7o da Constituição Federal (BRASIL, 1988).

Em entrevista dada ao Jornal Diário do Nordeste, Luma Andrade, professora da UNILAB, Universidade da Integração Internacional da Lusofonia Afro-Brasileira, relatou muitas dificuldades enfrentadas em seu trabalho quando professora do Ensino Médio. Segundo ela, muitas vezes os gestores da escola tentaram criar situações para retirá-la da escola. Contudo, a discriminação sofrida atua hoje como paradigma após ter sido a primeira travesti brasileira a conquistar o título de Doutora, em 2012. A professora ressalta a importância do título quanto à quebra do paradigma de a travesti ser vista apenas como profissional do sexo.

No artigo "LGBT e Mercado de Trabalho: Uma trajetória de preconceitos e discriminações", Moisés Santos de Menezes, Antônio Carlos de Oliveira e Ana Paula Leite Nascimento afirmam:

Além desse fator, outro muito comum, exigido mesmo que de forma indireta, é analisar se a postura ou comportamento do candidato LGBT à vaga de trabalho se apresenta como 'inadequada', 'destoante' ou 'inapropriada' para a empresa, firmando-se em um modelo heterossexual de ser e agir... As principais dificuldades expostas por LGBT para conseguir um emprego ou firmar-se em uma profissão estão bastantes presentes na vida daquelas pessoas que declaram sua orientação sexual ou identidade de gênero divergentes dos padrões heteronormativos. 
Relatam ainda que o sofrimento no âmbito laboral está diretamente associado aos estereótipos construídos socialmente relacionados à imagem de pessoas LGBT. Dessa maneira, existe uma constante rejeição desses sujeitos nos processos de seleção... As consequências negativas tanto em relação à ausência do acesso da população LGBT ao mercado de trabalho quanto pelas diversas situações preconceituosas e discriminatórias vivenciadas por esses sujeitos nesses ambientes provocam situações agravantes: depressão, insônia, sentimento de impotência, rejeição, exclusão, isolamento social, dentre outras (MENEZES, OLIVEIRA, NASCIMENTO, 2013, p. 33).

É nesse sentido que Thina Rodrigues, Coordenadora da Seção de Diversidade Sexual da Prefeitura de Fortaleza afirma: "Quando se trata de travesti ou transgênero você precisa de apadrinhamento para ingressar no mercado de trabalho. Sem uma pessoa influente dificilmente você consegue uma colocação" (DIÁRIO DO NORDESTE, 2015, p.1). E pontua: “É por isso que muitos optam por levar uma vida dupla. Movidos pela ignorância, grande parte da população brasileira acredita que LGBTs fazem algo errado, então é difícil, mas não impossível, que o enfrentamento do preconceito e a quebra de barreiras ocorram através das organizações" (DIÁRIO DO NORDESTE, 2015, p.1).

Segundo Puente-Palacios, Seidl e Silva: “A diversidade deve ser percebida tanto na condição de diferencial competitivo, como também enquanto oportunidade de convivência interpessoal. A cada dia estamos mais inseridos em um cenário onde pessoas diferentes se encontram, logo aproveitar as vantagens dessa diversidade é uma necessidade" (PUENTEPALACIOS, SEIDL e SILVA, 2008, p. 87).

\section{INICIATIVAS ORGANIZACIONAIS DE INCLUSÃO E RESPEITO À DIVERSIDADE}

Contudo, apesar de se depararem com situações rotineiras de violência, de resistência e intolerância, o que dificulta bastante a empregabilidade de LGBTs, além de levá-los para a informalidade, nos últimos anos começaram a despontar iniciativas organizacionais que ensejam nova perspectiva quanto à política de recrutamento e de seleção por parte de 
alguns órgãos e organizações, isso porque a orientação sexual diversa ainda motiva casos de não contratação, de demissão e embaraço nas promoções.

Com a finalidade de alocar/intermediar vagas de empregos para profissionais trans e travestis, a ativista transexual Daniela Andrade criou, em 2013, em parceria com a empresa norte-americana ThoughtWorks, o projeto Transempregos, site voltado para o cadastro de currículos e onde pode ocorrer um processo de mediação entre o cidadão transexual ou travesti e as empresas contratantes. Não se trata de intermediação dessa força de trabalho, pois ela apenas recebe currículos via e-mail e repassa as vagas disponíveis ao profissional que busca recolocação no mercado de trabalho, seja emprego com carteira assinada ou estágios. Além do banco de currículos para possíveis vagas, o site dispõe de informes para palestras coorporativas sobre diversidade em geral.

Também nesse sentido e atuando a fim de promover políticas de inserção dessas/es profissionais no mercado de trabalho, em 2015 a Prefeitura de São Paulo criou o projeto Transcidadania, incentivo financeiro mensal a travestis e trans que concluíram o ensino médio, a fim de terem acesso a cursos de qualificação profissional por até dois anos, com acompanhamento de psicólogos e advogados.

Em 2016, a Faculdade Baiana de Direito tornou público o processo seletivo exclusivo de recrutamento voltado para pessoas transgêneros a fim de integrarem o quadro de colaboradores fixos ${ }^{8}$ dessa instituição (GAUTHIER, 2017). Contudo, episódios ainda revelam

\footnotetext{
${ }^{8}$ A matéria intitulada Banco do Brasil terá de indenizar mãe de ex-funcionária trans que se matou, publicada pelo jornal Folha de S. Paulo, em 2 de dezembro de 2019, contou o relato da jovem Rebeca, transexual colaboradora do banco no interior paulista e que se submeteu à cirurgia de redesignificação: 'A juíza Ana Paula Alvarenga Martins, em sentença assinada no fim de setembro, condenou o Banco do Brasil a pagar $\mathrm{R} \$ 120$ mil de indenização por danos morais à mãe... Rebeca dispensou o aviso prévio na demissão. A carta em que pediu o desligamento apontava um despreparo da instituição para lidar com 'a questão da identidade de gênero' e aconselhava 'que haja estudo por parte da administração e diretoria do banco para evitar problemas futuros com outros /as funcionários'. O caso é abordado na peça de acusação: 'A trabalhadora, assim que chegou ao local de trabalho, foi chamada à sala da gerência, onde foi informada... que estava proibida de cumprimentar com beijo no rosto os colegas... A trabalhadora ainda tentou argumentar com o gerente, que reagiu grosseiramente e, em tom áspero, gritou: 'Eu sou a gerência!'. De outra gerente, segundo os advogados de sua mãe, ouviu: 'Não importa o que faça, você sempre será um homem, nunca será uma mulher de verdade' (FOLHA, 2019, p. 22).
} 
como algumas pessoas reagem sobre a abertura a essa questão. Em janeiro de 2014, um abaixo-assinado de funcionários reivindicaram que uma travesti, funcionária de uma lanchonete, deixasse de usar o banheiro feminino de um shopping em Salvador. Apesar da pressão, o Shopping Barra se recusou em atender o pedido. Eis a resposta da Organização:

Embora reconheça que muitos temas ainda sejam objeto de amadurecimento nas necessárias discussões da sociedade civil, não pretendemos adotar qualquer postura que venha a negar vigência a tal preceito geral de tutela da personalidade e, por consequência, ao próprio princípio constitucional da dignidade da pessoa humana (G1, 2017, p.1).

Por esse período, a Prefeitura de Salvador lançou a Secretaria da Reparação ${ }^{9}$, iniciativa que fixou normas e ações de afirmação e de vigilância ao cumprimento da lei, além de premiar organizações que têm apoiado uma maior inclusão de LGBTs.

Desde dezembro de 2017, a IBM oferece um plano de medicamentos que inclui tratamento com hormônios para pessoas que passam por cirurgias de sexo. O desconto ao Colaborador chega a 75\%. Além disso, casais homossexuais que adotam uma criança têm direito à licença maternidade de quatro meses, com extensão de sessenta dias: "Acreditamos que a pessoa é produtiva no trabalho apenas quando consegue ser $100 \%$ ela mesma. Por isso, damos todo o incentivo necessário para que a pessoa saia do armário", afirma Adriana da Costa Ferreira, líder de Diversidade e Inclusão da IBM para a América Latina.

Em Outubro de 2018, trinta e duas Empresas e organizações não governamentais se uniram e assinaram a Carta de Apoio à Diversidade, ao Respeito e à Inclusão de Pessoas LGBT+ nos Locais de Trabalho no Brasil. A ideia é reforçar o respeito à diversidade com o desenvolvimento de políticas que estabeleçam metas pelo fim do preconceito. Essa carta seguiu modelo similar criado pelo Instituto Ethos, que lançou, em 2013, O Compromisso das Empresas com os Direitos Humanos $L G B T$, documento que incentivava a promoção e o

${ }^{9}$ A Secretaria da Reparação é a instância da Prefeitura de Salvador responsável por articular, junto às instituições governamentais e não governamentais, políticas públicas de promoção racial, inclusão social e 
respeito à causa. O banco Citi, Dow, Uber e Linkedin, entre outros signatários dessa ação, firmaram acordo para promover ações de conscientização entre seus Colaboradores, visando oferecer mais acesso a públicos que sofrem discriminação, como pessoas trans. Há, ainda, cursos para liderança e extensão de benefícios aos cônjuges do mesmo sexo.

Da mesma forma, a rede de Supermercados Carrefour lançou uma Cartilha da Diversidade, que pode ser acessada no endereço eletrônico: https://www.carrefour.com.br/institucional/sustentabilidade/social/valorizamos-adiversidade.

A Linkedin, por exemplo, discute em reuniões semanais sobre como promover o respeito entre LGBTs, negros e PCDs (Pessoas com Deficiência) no ambiente de trabalho. Após o debate, as conclusões são enviadas aos Colaboradores. No caso do Citi, quando um colaborador é contratado precisa assinar um Termo de Conduta em que se compromete, entre outras coisas, a não ter preconceito com os demais colegas. "O respeito é uma construção de longo prazo. Como a gente fala muito sobre diversidade na empresa, nosso colaborador está habituado com isso no dia a dia", afirma Felipe Cotta, Superintendente de Recursos Humanos do banco. Com cerca de dois mil funcionários no país, o banco estima que 3\% dos seus colaboradores sejam gays. O banco Citi apoia a Parada do Orgulho Gay de São Paulo, além de manter um canal interno de reclamações para pessoas vítimas de discriminação.

Desde então, a Uber Brasil apoia eventos em torno da diversidade em diversas capitais brasileiras, além de recentemente desenvolver um Programa de inclusão que concede descontos a motoristas trans que queiram dirigir na plataforma. Por fim, a Organização Kaizen Talentos Humanos possui um projeto para a inclusão e recolocação desses profissionais no mercado de trabalho junto a algumas empresas parceiras. $\mathrm{O}$ projeto tem o

valorização da diversidade. Em março de 2016, a Prefeitura de Salvador lançou o Centro Municipal de Referência LGBT, a fim de atuar em conjunto com o Observatório da Discriminação Racial e LGBT. 
ideal de formar e engajar organizações a incorporarem o discurso da diversidade em seus ambientes de trabalho, passando a fazer parte do combate à discriminação.

$E$, seguindo o alcance de ações afirmativas para além das raciais (deflagrada há alguns anos em todos os estados brasileiros), a UNEB, Universidade do Estado da Bahia, aprovou, em Julho de 2018, um sistema de percentual de vagas para travestis, transexuais, indígenas, quilombolas, ciganos, PCDs e pessoas com transtorno do espectro autista.

Eis, portanto, iniciativas que reorientam o Brasil para um país mais inclusivo, menos intolerante e que respeita a diversidade de uma nação com mais de 200 milhões de pessoas.

\section{CONSIDERAÇÕES FINAIS}

Se o Legislativo brasileiro falha por não legislar e se o Estado não tem oferecido uma política de proteção condizente a um contingente tão numeroso quanto vulnerável, por outro lado, leis, normas e portarias impostas pelo Supremo Tribunal Federal e iniciativas que começam a ser desenvolvidas por algumas organizações indicam um caminho lento e gradual de mais respeito e aceitação de pessoas historicamente excluídas, inclusive pelas suas famílias, como são os casos da maioria dos LGBTs brasileiros. É dessa forma que, se o mundo corporativo ainda reflete uma realidade repleta de episódios de preconceito, por outro lado, também começa a desenvolver ações de educação e espaços de capacitação técnica, profissional e de empreendedorismo voltados à geração de renda e à inserção desse grupo no mercado de trabalho formal. O raciocínio é que organizações que não realizam políticas internas de respeito a LGBTs com frequência verificam aumento na violência e disseminação do preconceito generalizado em seus ambientes de trabalho.

Assim, órgãos públicos, ONGs e organizações as mais diversas têm impulsionado políticas inclusivas não apenas de orientação sexual, mas, também, voltadas para pessoas de baixa renda, negras, mulheres, PCDs etc. São ações que despontam em todas as regiões do Brasil e que tentam enfrentar o preconceito através da criação de oportunidades de trabalho 
e da promoção de cursos, treinamentos e discussões em diversas áreas do mercado.

Este artigo lançou reflexões a partir da revisão de leis internacionais e nacionais e sobre como a comunidade LGBT tem lutado para conquistar mais espaço no mercado de trabalho formal. Como vimos, a impressão é que, embora ainda exista forte resistência nos processos de recrutamento e contratação em seleções de estágios e empregos, reflexo da sociedade contemporânea brasileira, também começa a vigorar nas organizações uma nova consciência, percebida em práticas baseadas na educação, na aceitação e no respeito às escolhas das pessoas e suas respectivas formações profissionais.

\section{REFERÊNCIAS BIBLIOGRÁFICAS}

ARÁN, Márcia e MURTA, Daniela. Do diagnóstico de transtorno de identidade de gênero às redescrições da experiência da transexualidade: uma reflexão sobre gênero, tecnologia e saúde. Physis [online]. 2009, vol.19, n.1, pp. 15-41. ISSN 0103-7331.

BASÍLIO, Patrícia. Empresas dizem 'sim' à contratação de funcionários LGBTs no Brasil. São Paulo, Revista Época, 2 de Outubro de 2018.

BATISTA, Everton Lopes; BARBON, Júlia. Pequenas empresas se abrem para receber funcionários transexuais. Disponível: < http://www1.folha.uol.com.br/mercado/2017/08/1911077-pequenas-empresas-se-abrempara-receber-funcionarios-transexuais.shtml>. Acesso em: 21 dez. 2017.

BRASIL. Constituição da República Federativa do Brasil de 1988. Disponível: <http://www.planalto.gov.br/ccivil_03/constituicao/constituicaocompilado.htm>. Acesso em: 10 dez. 2017.

BUTLER, Judith. Desdiagnosticando o gênero. Physis [online]. 2009, vol.19, n.1, pp. 95-126.

BUTLER, Judith. Problemas de gênero: Feminismo e subversão da identidade. Rio de Janeiro: Civilização Brasileira, 2003.

CHIAVENATO, Idalberto. Gestão de pessoas - O Novo Papel dos Recursos Humanos nas Organizações. Rio de Janeiro: Campus, 1999.

CHIAVENATO, Idalberto. Teoria Geral de Administração. Rio de Janeiro: Elsevier, 2004. 
DIÁRIO DO NORDESTE. Homofobia: Discriminação profissional. Disponível em: <http://diariodonordeste.verdesmares.com.br/especiais/homofobia-preconceito-notrabalho-1.1280951>. Acesso em 10 jan. 2018.

FELIPE, Jane. Representações de gênero, sexualidade e corpo na mídia. Revista Tecnologia e Sociedade, Curitiba, v. 1, p. 41-54. 2006.

FOLHA DE S. PAULO. Banco do Brasil terá de indenizar mãe de ex-funcionária trans que se matou. São Paulo: 2019, p. 22.

FLEURY, A. R. D. e TORRES, A. R. R. Homossexualidade e Preconceito: o que pensam os futuros gestores de pessoas. Curitiba: Juruá, 2010.

G1. Funcionários pedem que travesti não use banheiro feminino em shopping. Disponível: < http://g1.globo.com/bahia/noticia/2014/01/funcionarios-pedem-que-travesti-nao-usebanheiro-feminino-em-shopping.html>. Acesso em: 18 dez. 2017.

G1. Transexuais enfrentam barreiras para conseguir aceitação no mercado de trabalho. Disponível: < https://g1.globo.com/economia/concursos-e-emprego/noticia/transexuaisenfrentam-barreiras-para-conseguir-aceitacao-no-mercado-de-trabalho.ghtml >. Acesso em: 10 dez. 2017.

GAUTHIER, Jorge. Faculdade Baiana de Direito abre seleção para contratar pessoas trans. Disponível: < http://blogs.correio24horas.com.br/mesalte/faculdade-baiana-de-direito-abreselecao-para-contratar-pessoas-trans/>. Acesso em: 21 dez. 2017.

INSTITUTO ETHOS. O Instituto. Disponível: < https://www3.ethos.org.br/conteudo/sobre-oinstituto/\#.WI_veLynHIU>. Acesso em: 21 dez. 2017.

LAPA, Nádia. 0 preconceito contra transexuais no mercado de trabalho. In: Carta Capital. 2013. Disponível em: http://www.cartacapital.com.br/blogs/feminismo-pra-que/opreconceito-contra-transexuais-no-mercado-de-trabalho-2970.

LOURO, Guacira Lopes. Curriculo, Gênero e Sexualidade. Porto: Porto Editora, 2000.

LOURO, Guacira Lopes. Um corpo estranho, ensaios sobre sexualidade e teoria queer. Belo Horizonte: Autêntica. 2004.

MARTÍ, Silas. Trump tira de transgêneros proteção contra discriminação no trabalho. Disponível: < http://www1.folha.uol.com.br/mundo/2017/10/1924843-trump-tira-detransgeneros-protecao-contra-discriminacao-no-trabalho.shtml>. Acesso em: 18 jan. 2018.

MASLOW, Abraham. Introdução á psicologia e ser. Rio de Janeiro: Eldorado, 1999. 
MECCHI, Cassiano Luiz. Diversidade sexual e políticas de gestão de pessoas: um estudo exploratório em três empresas de grande porte. In: Natal: EnGPR, 2007.

MENEZES, Moisés Santos de; OLIVEIRA, Antonio Carlos de; NASCIMENTO, Ana Paula Leite. LGBT E MERCADO DE TRABALHO: UMA TRAJETÓRIA DE PRECONCEITOS E DISCRIMINAÇÕES. Conqueer - Conferência Internacional de Estudos Queer. Rio de Janeiro: Abril de 2013.

MISKOLCI, Richard. A Teoria Queer e a Sociologia: O desafio de uma analítica de normalização. Sociologias, Porto Alegre, ano 11, n. 21, jan/jun., p. 150 -182, 2009.

MOTT, Luiz. Homoafetividade e direitos humanos. Estudos feministas, Florianopólis, v.14, n.2, 2006.

NETO, Alcino Leite. Transexual brasileira vira estrela política. Disponível: <

http://www1.folha.uol.com.br/fsp/mundo/ft2212200216.htm>. Acesso em: 10 dez. 2017.

OLIVON, Beatriz. Os melhores países para os gays. Disponível: < https://exame.abril.com.br/mundo/os-melhores-paises-para-os-gays/>. Acesso em: 18 jan. 2018.

ONUBR. Violência contra pessoas trans é 'extremamente alta' nas Américas, apontam ONU e parceiros. Disponível: < https://exame.abril.com.br/mundo/os-melhores-paises-para-osgays/>. Acesso em: $10 \mathrm{dez} .2017$.

PUENTE-PALACIOS, SEIDL, Juliana e SILVA, Rafael Almeida Dutra. Ser ou parecer diferente: o papel da diversidade na satisfação de equipes de trabalho. Florianópolis: Revista Psicologia, Organizações e Trabalho. Agosto de 2008, p. 87.

PORTAL VERMELHO. LGBT no Congresso alerta contra o ódio e o preconceito. Disponível: <http://www.vermelho.org.br/noticia/278221-8>. Acesso em: 10 dez. 2017.

REINAUDO, Franco e BACELLAR, Laura. O mercado GLS: Como obter sucesso com o segmento de maior potencial da atualidade. São Paulo: Ideia \& Ação, 2008.

SILVA, Joseli Maria (Org.). Geografias Subversivas: discursos sobre espaço, gênero e sexualidade. Ponta Grossa: Todapalavra, 2009.

TRANSEMPREGOS. Visão. Disponível: < http://www.transempregos.com.br/sobre.php>. Acesso em: 10 dez. 2017.

UNIC. O que são os direitos humanos? Disponível em: http://unicrio.org.br/. Acesso em: 12 nov. 2017. 